\title{
Perillyl alcohol inhalation concomitant with oral temozolomide halts progression of recurrent inoperable glioblastoma: a case report
}

\author{
Clovis O Da Fonseca'1, Igor Petrone Soares², Daniele Sousa Clemençon³ ${ }^{3}$ Sheila Rochlin ${ }^{4}$, Leon Cardeman ${ }^{5}$ and Thereza Quirico-Santos²*
}

*Correspondence: tquirico@vm.uff.br

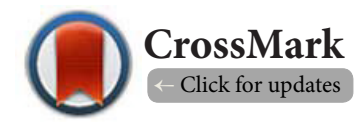

\begin{abstract}
'Department of General and Specialized Surgery, Fluminense Federal University, Rio de Janeiro, Brazil. 2Department of Cellular and Molecular Biology, Institute of Biology, Fluminense Federal University, Rio de Janeiro, Brazil. ${ }^{3}$ Service of Neurosurgery, Getulio Vargas Estate Hospital, Rio de Janeiro, Brazil. ${ }^{4}$ Service of Anatomopathology, Fernando Magalhães Town Hospital, Rio de Janeiro, Brazil. ${ }^{5}$ Department of Pathology, Rio de Janeiro Federal University, UNIRIO, Rio de Janeiro, Brazil.
\end{abstract}

\begin{abstract}

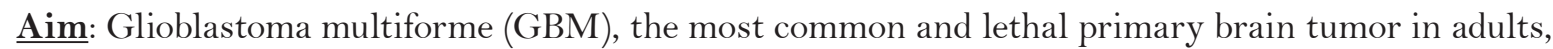
inevitably recurs despite standard of care, consisting of surgical resection, radiotherapy (RT), and alkylating temozolomide (TMZ). High content of the repair enzyme MGMT $\left(O^{6}\right.$-methylguanine-DNA methyltransferase) contributes to drug resistance and tumor recurrence. The monoterpene perillyl alcohol $(\mathrm{POH})$ induces apoptosis and cytotoxicity of TMZ-resistant and TMZ-sensitive glioma cells independently of MGMT expression.

Case presentation: We report the case of an adult patient with non-resected inoperable recurrent GBM that was successfully treated with POH inhalation in combination with oral TMZ, after failing to respond to standard treatment. A 51-year-old white woman with a sudden, intense and refractory headache with no underlying cause showed brain image (MRI) with diffusely infiltrating lesion, prominent edema, and marked mass effect with midline shift, consistent with inoperable high-grade malignant glioma in the right temporal lobe. A complex histological feature, characterized by ischemic necrosis and glomeruloid microvascular proliferation, confirmed the diagnosis of malignant glioma. Immunohistochemical evaluation showed marked EGFR (epidermal growth factor receptor) staining; active proliferative status was confirmed by high Ki67 and p21 expression; there was strong p53 tumor suppressor labeling but faint cytoplasmic PTEN staining; expression of MLH1 and MSH6, two proteins associated with mismatch DNA repair and resistance to TMZ, was elevated. Indeed, 6 months after onset and despite specific treatment (RT+TMZ), this patient had tumor recurrence at same site. She developed adverse reactions including thrombocytopenia and resistance to alkylating TMZ, and was indicated for palliative treatment. The patient was then enrolled (December 2012) in the clinical trial for treatment with $\mathrm{POH}$ inhalation concomitant with $300 \mathrm{mg}$ TMZ oral schedule during 5 days. MRI scans performed 3, 7, 12 and 24 months later (December 2012 to December 2014) revealed marked reduction of enhancing lesion without further recurrences.
\end{abstract}

Conclusion: Despite increased expression of DNA repair proteins supporting drug resistance, combined POH+TMZ therapy reduced tumor mass, halted tumor recurrence, and increased patient's survival. This case highlights the therapeutic efficacy of combined POH intranasal administration with systemic TMZ in a patient with non-resected inoperable GBM, who failed prior therapy and was under supportive treatment.

Keywords: Perillyl alcohol, intranasal administration, glioblastoma multiforme, combination therapy, temozolomide, drug resistance

\section{Introduction}

Overall survival of patients with glioblastoma or grade IV glioma
(GBM) is limited to just a few months, even after treatment with advanced strategies, including debulking surgery and adjuvant

(C) 2015 Quirico-Santos et al; licensee Herbert Publications Ltd. This is an Open Access article distributed under the terms of Creative Commons Attribution License (http://creativecommons.org/licenses/by/3.0). This permits unrestricted use, distribution, and reproduction in any medium, provided the original work is properly cited. 
therapy consisting of radiation therapy (RT) and chemotherapy, followed by combined radio-chemotherapy with alkylating drugs to destroy residual tumor cells [1-3]. The alkylating agent temozolomide (TMZ) is able to bypass the blood-brain barrier (BBB) and has become the gold standard chemotherapy for glioblastoma [4]. Failure to treatment is mainly related to indefinite borders of the lesion with unnoticed tumor cell infiltration and extensive neoangiogenesis into the surrounding tissue, preventing accurate complete surgical removal. A better prognosis is associated with younger age, extensive surgical resection, and efficient response to TMZ and RT. Yet, there is no ordinary treatment for tumor recurrence after patients' failure to respond to combined radio-chemotherapy. Further progression to a poor outcome within a few months [1] could be partly related to the content of highly tumorigenic, radioresistant glioma stem cell that differs between tumors with the same histological type [5].

Particularly important in GBM is the methylation status of cellular DNA repair protein $\mathrm{O}^{6}$-methylguanine-DNA methyltransferase (MGMT) that removes mutagenic alkylation adducts from the $O^{6}$ position of guanine, thereby causing resistance to alkylating drugs $[6,7]$. TMZ and other alkylating agents modify the $\mathrm{O}^{6}$-position in guanines, thus forming critical DNA cross-link lesions that arrest cell proliferation. Methylation of the promoter silences the MGMT gene, and this is a predictive factor for therapy response and survival of GBM patients treated with TMZ and RT [8]. Once GBM patients become resistant to $T M Z$, there are very limited treatment options available. Besides, glioma cells often present multiple gene mutations, oncogene activation, and/or loss of tumor suppressor genes required for encoding proteins critical in signal transduction pathways. Indeed, Ras-RAF-ERK hyperactivity due to increased activity of EGFR and PDGFR upstream regulators is essential for maintenance of glioma cells [9-11]. Moreover, amplification of the EGFR gene results in overexpression of the transmembrane tyrosine kinase EGFR and its EGFRvIll variant, which is characterized by a truncated extracellular domain with ligand-independent constitutive activity [12]. Therefore a pharmacological-based therapy with the monoterpene perillyl alcohol (POH), which inhibits FTase (farnesyl transferase) activity $[10,13]$ and Ras/mTOR signaling pathways, but induces cytotoxicity in TMZ-resistant and TMZsensitive glioma cells independently of MGMT expression, may be a suitable approach limiting glioma cell proliferation [14-16]. $\mathrm{POH}$ is a naturally occurring monoterpene that exerts significant antitumor activity and has been used orally in several clinical trials [17-19]. However, when administered orally, $\mathrm{POH}$ therapy is associated with dose-limiting adverse effects. Standard chemotherapeutic protocols for brain tumors are frequently inefficient, mostly due to the inability of drugs to reach and maintain effective concentrations within the brain tissue for an appropriate length of time $[20,21]$.

The intranasal route provides a practical, noninvasive method for transportation of lipophilic and apolar drugs straight to the central nervous system (CNS), thus bypassing the BBB, minimizing systemic exposure, and dramatically reducing adverse side effects [20-23]. The role of the olfactory epithelium as a gateway for substances entering the CNS lead us to develop a novel and ground-breaking methodology for $\mathrm{POH}$ delivery to treat patients with malignant brain tumors $[22,23]$. Long-term administration of $\mathrm{POH}$ as a single agent by inhalation treatment of patients with recurrent malignant glioma substantially increased survival rate with virtually no adverse side effects. Inasmuch radiation-induced injury creates a favorable niche for proliferation of highly tumorigenic radioresistant glioma stem cell clusters associated with perivascular and/or necrotic regions, independently of the patient's MGMT and p53 status [24], it was important to assess the therapeutic efficacy of combined $\mathrm{POH}$ intranasal administration with systemic TMZ in a patient with inoperable GBM, who had failed prior standard of care therapy and was under supportive treatment.

\section{Case presentation}

The present study was approved by the University Hospital Ethics Committee and the Brazilian Ministry of Health (CONEP 9681 no. 124 25000.009267/2004-25), and was carried out in the Hospital Medical School of the Fluminense Federal University. Before inclusion in the protocol, the patient signed a written informed consent to enroll in the Phase I/II clinical trial. $\mathrm{POH}$ was formulated for inhalation delivery and the preparation supplied by the Multidisciplinary Laboratory of Pharmaceutical Sciences at Rio de Janeiro Federal University, according to US Patent Application 20040087651 May 6, 2004, and BR Patent Number PI0107262-5. POH (55 mg; 0.3\% v/v) was administered by inhalation 4 times daily, totaling 266.8 $\mathrm{mg} /$ daily.

A 51-year-old white woman, with no significant past medical record and without family history of brain tumor or neurological disease, complained of sudden and intense headache that did not improve with analgesics. The patient was then referred to the neurological emergency outpatient unit (April 2012), where magnetic resonance imaging (MRI) of the brain with and without contrast (Figure 1) revealed a highly infiltrating lesion in the right temporal lobe that enhanced with gadolinium. The large irregular space-occupying lesion with prominent edema and marked mass effect with midline shift was consistent with a diffuse high-grade malignant tumor in the right temporal lobe. The tumor was considered as non-resected GBM meaning that could not be surgically removed without risking extensive neurological damage. Therefore patient underwent a stereotactic needle biopsy and histological analysis carried out by three different pathologists, further confirming the diagnostic of malignant glioma (GBM). The tumor lesion presented hy-percellularity with marked nuclear atypia/pleomorphism, hypercromatic nuclei (Figure 2A), hemorrhage, ischemic necrosis and microvascular proliferation (Figure 2B), with tumor cells showing intense EGFR (epidermal growth factor receptor) 


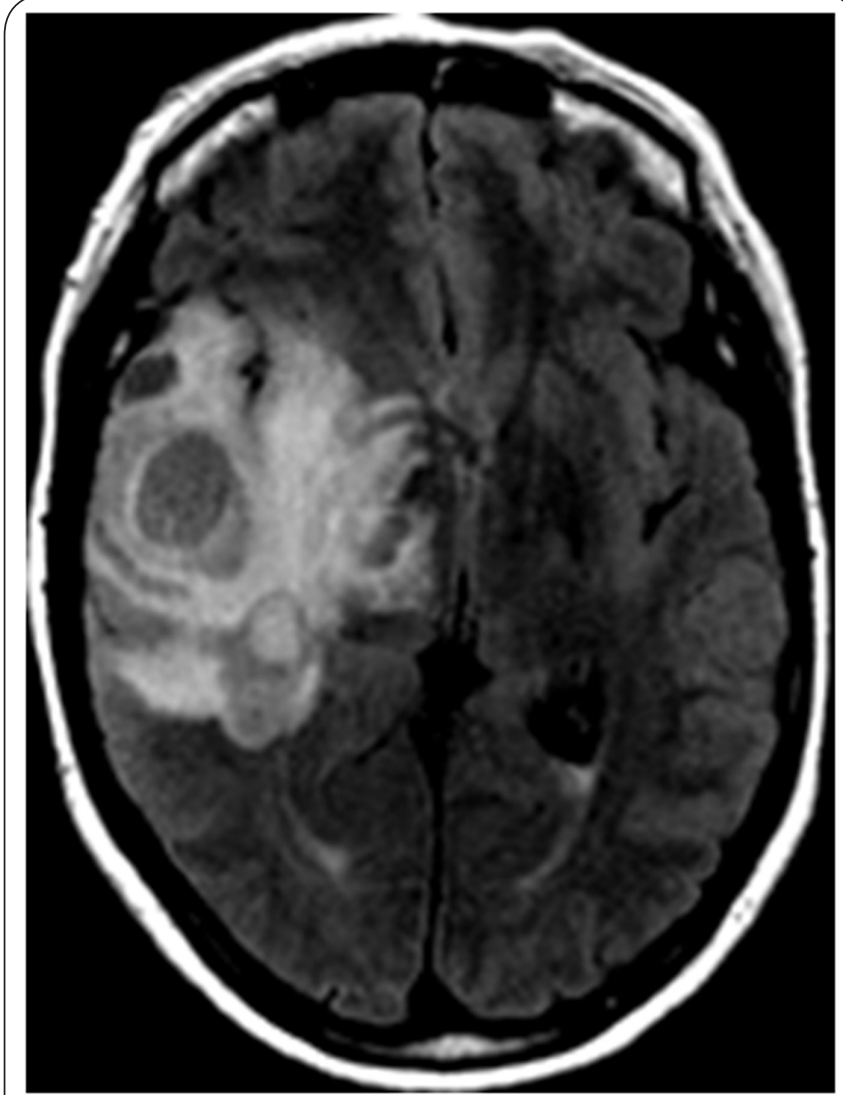

Figure 1. Brain MRI at onset of disease T1-weighted axial gadolinium-enhanced magnetic resonance image shows an enhancing tumor with infiltrating pattern in the right frontal lobe, prominent edema and marked mass effect with midline shift consistent with a high-grade malignant tumor.

staining (Figure 2C). Further immunohistochemical analysis showed features (Figure 3 ) indicating that glioma cells had active proliferative status, characterized by high Ki67 (Figure 3A) and p21 (Figure 3B) expression; furthermore, there was high tumor suppressor p53 (Figure 3C) but faint cytoplasmic PTEN (Figure 3D) staining. In addition, glioma cells also showed strong staining for MLH1 (Figure 3E) and MSH6 (Figure 3F) mismatch DNA repair proteins. Such pattern was characteristic of hypoxic conditions (e.g., ischemic necrosis), where PTEN and p53 work in tandem to induce maspin, a tumor suppressor protein involved in sensitizing cells to chemotherapy [25].

From May to July 2012, the patient received radiation therapy (59.4 Gy total) concomitant with TMZ (150-200 mg/m²/day) chemotherapy on a 28-day cycle schedule. This combined therapy ( $R T+T M Z$ ) reduced tumor mass (Figure $4 \mathrm{~A}$ ), but did not cause any further changes on brain MRI taken few months later (Figure 4B). Indeed, 6 months later (October 2012), a new brain MRI revealed tumor recurrence, showing a large and infiltrative lesion in the right temporal lobe (Figure 5A). Patient then started additional TMZ (150-200 mg/m²/day) cycle, but treatment had to be discontinued (November 2012)

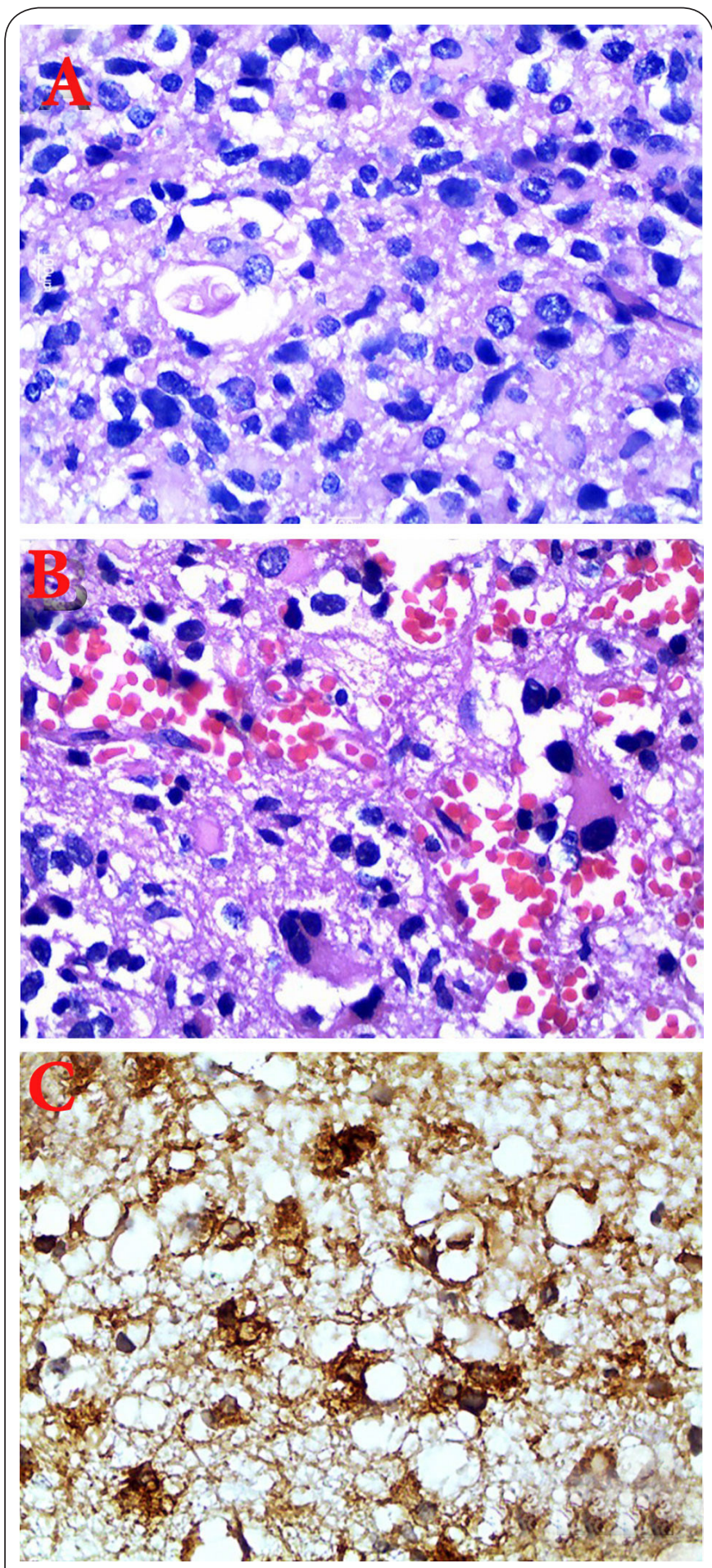

Figure 2. Tumor lesion from primary GBM stained with hematoxylin-eosin shows.

(A). Hypercellularity with nuclear atypia, hypercromatic nuclei and pleomorphism. Note (B) The prominent microvascular proliferation, hemorrhage and ischemic necrosis.

(C). Depicts glioma cells with overexpression of EGFR (EGFR pharmDx ${ }^{\mathrm{TM}}$, Dako) that specifically detects the transmembrane receptor encoded by HER 1 gene critical for tumor proliferation. $\mathrm{x} 400$, Scale bar $100 \mu \mathrm{m}$. 


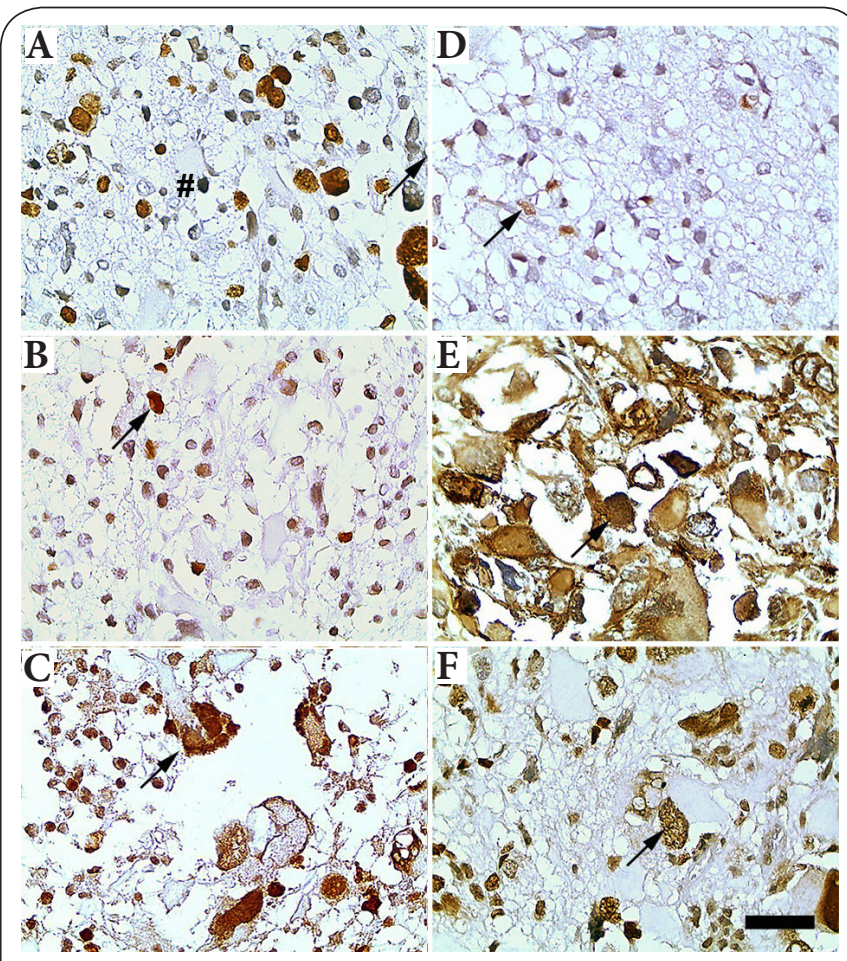

Figure 3. Pattern of immunohistochemical staining for (A) Ki67, (B) p21, (C) wild-type p53, (D) PTEN, (E) proteins associated with mismatch DNA repair genes MLH1, (F) MSH6 in formalin-fixed paraffin embedded biopsy tumor lesion. Arrows show positive staining. x400; Scale bar $100 \mu \mathrm{m}$.

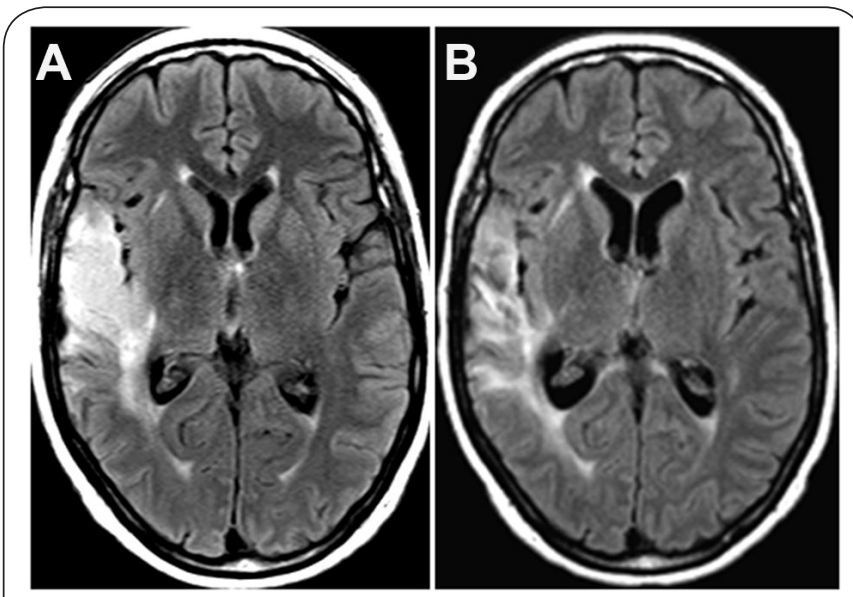

Figure 4. (A). Combined therapy (RT-TMZ) reduced tumor mass. (B). Did not cause any further changes on brain MRI taken few months later.

due to side effects with adverse reactions (nausea, vomiting, headache), thrombocytopenia $\left(43,000 / \mathrm{mm}^{3}\right)$ but not neutropenia or altered hepatic function. At that time, patient was considered out of therapeutic possibilities and indicated for supportive (palliative) treatment. Subsequently (December 2012), the patient was enrolled in the Phase I/II clinical
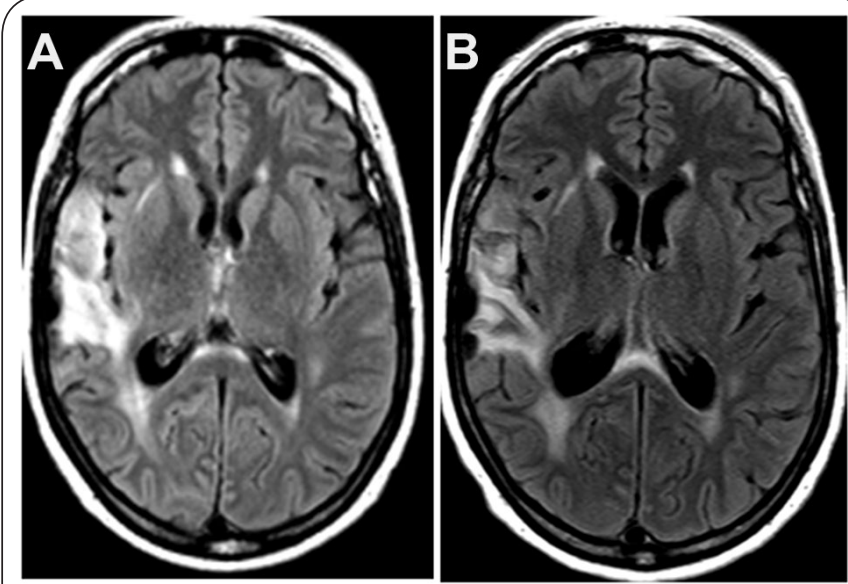

Figure 5. MRI shows tumor recurrence 6 months

(December/2012) after RT-TMZ (A) with large and infiltrative lesion in the right temporal lobe, and reduction of tumor lesion (B) in July/2013 after combined POH-TMZ treatment.

trial for treatment with $\mathrm{POH}$ inhalation concomitant with $300 \mathrm{mg}$ TMZ oral schedule during 5 days, because she had normalized platelets count $\left(350,000 / \mathrm{mm}^{3}\right)$ without evidence of myelossupression (red blood cells 4,7 million $/ \mathrm{mm}^{3}$; leukocyte count $7,980 / \mathrm{mm}^{3}$ ). Since then, combined POH+TMZ treatment has efficiently reduced tumor size (Figure $5 \mathrm{~B}$ ) and improved clinical condition without any neurological symptoms related to tumor recurrence or clinical adverse effects to treatment. From December 2012 up to now (December 2014), the patient has remained in good health under exclusive $\mathrm{POH}$ inhalation therapy combined with TMZ schedule, without any evidence of tumor recurrence, and only taking anti-seizure medication but no steroidal drugs. Recent clinical laboratory analysis showed hematologic and biochemical parameters within normal range values, without any signs of neurologic, hepatic and renal toxicity or clinical adverse effects.

\section{Discussion}

GBM is an aggressive heterogeneous brain tumor in adults with distinct histologic and molecularly features accordingly to their presumed cell of origin and extent of brain infiltration $[26,27]$. Its dismal prognosis is partly due to increased angiogenesis and altered brain microvascular permeability leading to extensive vasogenic peritumoral edema. The novelty in this report relates to the efficacy of combined POH+TMZ treatment in a patient with recurrent inoperable malignant glioma. At the onset, histological analysis of the tumor lesion showed pleomorphism with increased mitotic activity, pseudopalisading necrosis and microvascular proliferation. Marked EGFR expression confirmed the characteristic of highly malignant glioma. Additionally, EGFR amplification, high p53 but weak PTEN cytoplasmic staining, was a pattern characteristic of hypoxic conditions associated with ischemic necrosis [25]. Moreover, high MLH1 and MSH6 staining of proteins associated with 
mismatch DNA repair processes, which was present at the onset of disease, was a predictive factor partly responsible for resistance to TMZ alkylating chemotherapy and this patient's successive recurrence $[6,7,14]$.

Standard treatment of malignant glioma with maximal surgical resection, followed by $\mathrm{RT}$ and concomitant adjuvant cytotoxic DNA alkylating drugs, is limited due to adverse side effects, and to date lacks curative potential. Moreover, combined RT and TMZ treatment may select a relatively quiescent subset of glioma stem cells responsible for sustaining the production of highly proliferative tumor cells [28] ensuing relapse or progression, and resulting in 3 to 9 months overall survival range [2]. GBM recurrence and drug resistance is associated with modification of enzymes, non-coding RNAs and cell mutations in different cell types from the original glioma cell $[\mathbf{2 7}, \mathbf{2 9}]$. The occurrence of treatment resistance for GBM patients is frequently associated to the overexpression of MGMT ( $\mathrm{O}^{6}$-methyl-guanine DNA methyltransferase), a DNA repair protein that removes alkyl groups located at the $\mathrm{O}^{6}$-position of guanine [30-32], but loss of the transcription factor GATA4, a negative regulator of normal astrocyte proliferation, may also trigger glioma formation due to promoter hypermethylation and/or induction of novel somatic mutations [33]. Indeed, elevated levels of alkyl purine DNA glycosylase (APNG) other DNA base excision repair enzyme that directly repairs alkylated bases at N7 guanine and N3 adenine is associated with poor overall survival [33].

In the phase I/II clinical trials conducted by our group in adult glioma patients, the $6.3 \mathrm{mg} / \mathrm{kg} \mathrm{POH}$ dosage administered by intranasal route on a long-term basis was safe, reduced tumor growth, and caused significant increase in overall survival of patients with recurrent malignant glioma [23]. Herein we report the efficacy of combined and prolonged $\mathrm{POH}+\mathrm{TMZ}$ treatment for non-resected recurrent, inoperable GBM that had failed previous standard therapy. $\mathrm{POH}$ is an effective radio- and chemosensitizer [34] that arrests glioma cells in G2/M phase of the cell cycle, up-regulates the proapoptotic Bax protein, presents anti-angiogenic properties [35], and also exerts cytotoxicity to TMZ-resistant and TMZsensitive glioma cells independently of $0^{6}$-methylguanine-DNA methyltransferase (MGMT) expression [14,36]. In addition to anti-angiogenic and antioxidant activities, $\mathrm{POH}$ markedly suppress proinflammatory cytokine production and NFk-B activation that strongly intensify neuroinflammation and cell damage [37], and further mediates neuroprotection in the experimental model of ischemia-reperfusion [36]. The mechanisms of radiation-induced injury are not yet understood, although radionecrosis is a continuous process associated with endothelial cell dysfunction due to tissue hypoxia and necrosis, with concomitant release of proangiogenic factors inducing vasogenic edema and progressive BBB dysfunction [2]. Besides, hypoxic conditions induced by radiation most likely enhanced cellular features rendering glioma stem cells resistant to treatment [24]. Moreover, increased proliferative state and extensive necrosis activated an angiogenic switch characterized by marked EGFR wild-type expression and signaling, and production of proangiogenic factors by both glial tumor and stromal cells. Regardless of increased expression of DNA repair proteins that are known to contribute to TMZ resistance, combined $\mathrm{POH}+\mathrm{TMZ}$ was capable of reducing tumor mass, halting tumor recurrence, and increasing patient's survival. Such strategy may be a suitable therapeutic approach for the treatment of MGMT-positive glioma patients.

\section{Conclusion}

The main obstacle in effective treatment of malignant gliomas is the restricted drug access to the intracranial tumor site partly related to the drugs' molecular weight and presence of polar functional groups. Herein we demonstrate the efficacy of combined $\mathrm{POH}+\mathrm{TMZ}$ treatment in a patient with recurrent non-resected inoperable malignant glioma. Regardless of existing resistance to $\mathrm{TMZ}$ alkylating drug, this novel therapeutic strategy reduced tumor invasion and discontinued further tumor recurrences for more than 24 months without obvious toxic side effects. Development of hybrid molecules containing the monoterpene $\mathrm{POH}$ as a carrier conjugated to conventional drugs may be a promising new therapy to treat brain tumors, and preliminary preclinical studies with $\mathrm{POH}$ covalently conjugated to TMZ have revealed promising outcomes [30].

\section{List of abbreviations}

GBM: Glioblastoma multiforme

$\mathrm{POH}$ : Perillyl alcohol

TMZ: Temozolomide

RT: Radiotherapy

MGMT: $O^{6}$-methylguanine-DNA methyltransferase

Competing interests

The authors declare that they have no competing interests.

Authors' contributions

\begin{tabular}{|l|c|c|c|c|c|c|}
\hline Authors' contributions & COD & IPS & DSC & SR & LC & TQ \\
\hline Research concept and design & $\checkmark$ & -- & -- & -- & -- & $\checkmark$ \\
\hline Collection and/or assembly of data & $\checkmark$ & $\checkmark$ & $\checkmark$ & $\checkmark$ & $\checkmark$ & $\checkmark$ \\
\hline Data analysis and interpretation & $\checkmark$ & $\checkmark$ & -- & $\checkmark$ & $\checkmark$ & $\checkmark$ \\
\hline Writing the article & $\checkmark$ & -- & -- & -- & -- & $\checkmark$ \\
\hline Critical revision of the article & $\checkmark$ & -- & -- & -- & -- & $\checkmark$ \\
\hline Final approval of article & $\checkmark$ & $\checkmark$ & $\checkmark$ & $\checkmark$ & $\checkmark$ & $\checkmark$ \\
\hline Statistical analysis & -- & -- & -- & -- & -- & -- \\
\hline
\end{tabular}

Acknowledgement and funding

The authors thank Dr Roberto Toledo for helpful discussion and Dr Axel H. Schönthal from University of Southern California, USA for critical reading and linguistic improvement of the manuscript. This study was supported in part by grants from National Council Research (MCT/CNPq/CT-Saude 401943/20100; CNPq/Universal 481059/2011-3), Rio de Janeiro Research Foundation (FAPERJ: E-26/110.329/2011; E-26/110.948/2013), FOPESQ-UFF, and Euclides da Cunha Foundation-UFF. 


\section{Publication history}

Editor: Han-Seung yoon, lida Municipal Hospital, Japan.

EIC: Giuseppe Musumeci, University of Catania, Italy.

Received: 13-Jan-2015 Final Revised: 14-Apr-2015

Accepted: 25-Apr-2015 Published: 04-May-2015

\section{References}

1. Stupp R, Mason WP, van den Bent MJ, Weller M, Fisher B, Taphoorn MJ, Belanger K,Brandes AA, Marosi C and Bogdahn U. et al. Radiotherapy plus concomitant and adjuvant temozolomide for glioblastoma. $N$ Engl $J$ Med. 2005; 352:987-96. | Article | PubMed

2. Gil-Gil MJ, Mesia C, Rey M and Bruna J. Bevacizumab for the treatment of glioblastoma. Clin Med Insights Oncol. 2013; 7:123-35. | Article | PubMed Abstract | PubMed Full Text

3. Miyanaga T, Hirato J and Nakazato Y. Amplification of the epidermal growth factor receptor gene in glioblastoma: an analysis of the relationship between genotype and phenotype by CISH method. Neuropathology. 2008; 28:116-26. | Article | PubMed

4. Friedman HS, Kerby $\mathrm{T}$ and Calvert $\mathrm{H}$. Temozolomide and treatment of malignant glioma. Clin Cancer Res. 2000; 6:2585-97. | Article | PubMed

5. Baumann M, Krause $M$ and Hill R. Exploring the role of cancer stem cells in radioresistance. Nat Rev Cancer. 2008; 8:545-54. | Article | PubMed

6. Esteller M, Garcia-Foncillas J, Andion E, Goodman SN, Hidalgo OF, Vanaclocha V, Baylin SB and Herman JG. Inactivation of the DNA-repair gene MGMT and the clinical response of gliomas to alkylating agents. $N$ Engl J Med. 2000; 343:1350-4. | Article | PubMed

7. Cankovic M, Mikkelsen T, Rosenblum ML and Zarbo RJ. A simplified laboratory validated assay for MGMT promoter hypermethylation analysis of glioma specimens from formalin-fixed paraffin-embedded tissue. Lab Invest. 2007; 87:392-7. | Article | PubMed

8. Minniti G, Salvati M, Arcella A, Buttarelli F, D’Elia A, Lanzetta G, Esposito V, Scarpino S, Maurizi Enrici R and Giangaspero F. Correlation between 06-methylguanine-DNA methyltransferase and survival in elderly patients with glioblastoma treated with radiotherapy plus concomitant and adjuvant temozolomide. J Neurooncol. 2011; 102:311-6. | Article | PubMed

9. Magnus N, Garnier D and Rak J. Oncogenic epidermal growth factor receptor up-regulates multiple elements of the tissue factor signaling pathway in human glioma cells. Blood. 2010; 116:815-8. | Article | PubMed

10. Lo HW. Targeting Ras-RAF-ERK and its interactive pathways as a novel therapy for malignant gliomas. Curr Cancer Drug Targets. 2010; 10:8408. | Article | PubMed Abstract | PubMed Full Text

11. Gao Q, Lei T and Ye F. Therapeutic targeting of EGFR-activated metabolic pathways in glioblastoma. Expert Opin Investig Drugs. 2013; 22:1023-40. | Article | PubMed

12. Montano N, Cenci T, Martini M, D’Alessandris QG, Pelacchi F, Ricci-Vitiani L, Maira G, De Maria R, Larocca LM and Pallini R. Expression of EGFRvIll in glioblastoma: prognostic significance revisited. Neoplasia. 2011; 13:1113-21. | PubMed Abstract | PubMed Full Text

13. Sebti SM and Hamilton AD. Farnesyltransferase and geranylgeranyltransferase I inhibitors and cancer therapy: lessons from mechanism and bench-to-bedside translational studies. Oncogene. 2000; 19:6584-93. | Article | PubMed

14. Cho HY, Wang W, Jhaveri N, Torres S, Tseng J, Leong MN, Lee DJ, Goldkorn A, Xu T, Petasis NA, Louie SG, Schonthal AH, Hofman FM and Chen TC. Perillyl alcohol for the treatment of temozolomide-resistant gliomas. Mol Cancer Ther. 2012; 11:2462-72. | Article | PubMed

15. Feldkamp MM, Lau N, Roncari L and Guha A. Isotype-specific Ras. GTP-levels predict the efficacy of farnesyl transferase inhibitors against human astrocytomas regardless of Ras mutational status. Cancer Res. 2001; 61:4425-31. | Article | PubMed
16. da Fonseca CO, Linden R, Futuro D, Gattass CR and Quirico-Santos T. Ras pathway activation in gliomas: a strategic target for intranasal administration of perillyl alcohol. Arch Immunol Ther Exp (Warsz). 2008; 56:267-76. | Article | PubMed Abstract | PubMed Full Text

17. Bailey HH, Attia S, Love RR, Fass T, Chappell R, Tutsch $K$, Harris L, Jumonville A, Hansen R, Shapiro GR and Stewart JA. Phase II trial of daily oral perillyl alcohol (NSC 641066) in treatment-refractory metastatic breast cancer. Cancer Chemother Pharmacol. 2008; 62:149-57. | Article I PubMed

18. Yeruva L, Pierre KJ, Elegbede A, Wang RC and Carper SW. Perillyl alcohol and perillic acid induced cell cycle arrest and apoptosis in non small cell lung cancer cells. Cancer Lett. 2007; 257:216-26. | Article | PubMed

19. Chaudhary SC, Alam MS, Siddiqui MS and Athar M. Perillyl alcohol attenuates Ras-ERK signaling to inhibit murine skin inflammation and tumorigenesis. Chem Biol Interact. 2009; 179:145-53. | Article | PubMed

20. Caruso G, Caffo M, Alafaci C, Raudino G, Cafarella D, Lucerna S, Salpietro FM and Tomasello F. Could nanoparticle systems have a role in the treatment of cerebral gliomas? Nanomedicine. 2011; 7:744-52. | Article I PubMed

21. Dhuria SV, Hanson LR and Frey WH, 2nd. Intranasal delivery to the central nervous system: mechanisms and experimental considerations. J Pharm Sci. 2010; 99:1654-73. | Article | PubMed

22. da Fonseca CO, Schwartsmann G, Fischer J, Nagel J, Futuro D, QuiricoSantos T and Gattass CR. Preliminary results from a phase I/II study of perillyl alcohol intranasal administration in adults with recurrent malignant gliomas. Surg Neurol. 2008; 70:259-66. | Article | PubMed

23. da Fonseca CO, Simao M, Lins IR, Caetano RO, Futuro D and QuiricoSantos T. Efficacy of monoterpene perillyl alcohol upon survival rate of patients with recurrent glioblastoma. J Cancer Res Clin Oncol. 2011; 137:287-93. | Article | PubMed

24. Mannino $M$ and Chalmers AJ. Radioresistance of glioma stem cells: intrinsic characteristic or property of the 'microenvironment-stem cell unit'? Mol Oncol. 2011; 5:374-86. | Article | PubMed

25. Eitel JA, Bijangi-Vishehsaraei K, Saadatzadeh MR, Bhavsar JR, Murphy MP, Pollok KE and Mayo LD. PTEN and $\mathrm{p} 53$ are required for hypoxia induced expression of maspin in glioblastoma cells. Cell Cycle. 2009; 8:896-901. | Article | PubMed

26. Agnihotri S, Burrell KE, Wolf A, Jalali S, Hawkins C, Rutka JT and Zadeh G. Glioblastoma, a brief review of history, molecular genetics, animal models and novel therapeutic strategies. Arch Immunol Ther Exp (Warsz). 2013; 61:25-41. | Article | PubMed

27. Verhaak RG, Hoadley KA, Purdom E, Wang V, Qi Y, Wilkerson MD, Miller CR, Ding L, Golub T and Mesirov JP. et al. Integrated genomic analysis identifies clinically relevant subtypes of glioblastoma characterized by abnormalities in PDGFRA, IDH1, EGFR, and NF1. Cancer Cell. 2010; 17:98-110. | Article | PubMed Abstract | PubMed Full Text

28. Chen J, Li Y, Yu TS, McKay RM, Burns DK, Kernie SG and Parada LF. A restricted cell population propagates glioblastoma growth after chemotherapy. Nature. 2012; 488:522-6. | Article | PubMed Abstract | PubMed Full Text

29. Clarke J, Penas C, Pastori C, Komotar RJ, Bregy A, Shah AH, Wahlestedt $C$ and Ayad NG. Epigenetic pathways and glioblastoma treatment. Epigenetics. 2013; 8:785-95. | Article | PubMed Abstract | PubMed Full Text

30. Chen TC, Cho HY, Wang W, Barath M, Sharma N, Hofman FM and Schonthal AH. A novel temozolomide-perillyl alcohol conjugate exhibits superior activity against breast cancer cells in vitro and intracranial triple-negative tumor growth in vivo. Mol Cancer Ther. 2014; 13:118193. | Article | PubMed

31. Chen TC, Cho HY, Wang W, Nguyen J, Jhaveri N, Rosenstein-Sisson R, Hofman FM and Schonthal AH. A novel temozolomide analog, NEO212, with enhanced activity against MGMT-positive melanoma in vitro and in vivo. Cancer Lett. 2015; 358:144-51. | Article | PubMed

32. da Fonseca CO, Teixeira RM, Silva JC, J DESDGF, Meirelles OC, Landeiro 
Da Fonseca et al. Journal of Histology \& Histopathology 2015,

http://www.hoajonline.com/journals/pdf/2055-091X-2-12.pdf

JA and Quirico-Santos T. Long-term outcome in patients with recurrent malignant glioma treated with Perillyl alcohol inhalation. Anticancer Res. 2013; 33:5625-31. | Article | PubMed

33. Agnihotri S, Wolf A, Munoz DM, Smith CJ, Gajadhar A, Restrepo A, Clarke ID, Fuller GN, Kesari S, Dirks PB, McGlade CJ, Stanford WL, Aldape K, Mischel PS, Hawkins $C$ and Guha A. A GATA4-regulated tumor suppressor network represses formation of malignant human astrocytomas. J Exp Med. 2011; 208:689-702. | Article | PubMed Abstract | PubMed Full Text

34. Rajesh D, Stenzel RA and Howard SP. Perillyl alcohol as a radio-/ chemosensitizer in malignant glioma. J Biol Chem. 2003; 278:35968-78. | Article | PubMed

35. Loutrari H, Hatziapostolou M, Skouridou V, Papadimitriou E, Roussos C, Kolisis FN and Papapetropoulos A. Perillyl alcohol is an angiogenesis inhibitor. J Pharmacol Exp Ther. 2004; 311:568-75. | Article | PubMed

36. Tabassum R, Vaibhav K, Shrivastava P, Khan A, Ahmed ME, Ashafaq M, Khan MB, Islam F and Safhi MM. Perillyl alcohol improves functional and histological outcomes against ischemia-reperfusion injury by attenuation of oxidative stress and repression of COX-2, NOS-2 and NFkappaB in middle cerebral artery occlusion rats. Eur J Pharmacol. 2015; 747:190-9. | Article | PubMed

37. Khan $A Q$, Nafees $S$ and Sultana $S$. Perillyl alcohol protects against ethanol induced acute liver injury in Wistar rats by inhibiting oxidative stress, NFkappa-B activation and proinflammatory cytokine production. Toxicology. 2011; 279:108-14. | Article | PubMed

\section{Citation:}

Da Fonseca CO, Soares IP, Clemençon DS, Rochlin S, Cardeman L and Quirico-Santos T. Perillyl alcohol inhalation concomitant with oral temozolomide halts progression of recurrent inoperable glioblastoma: a case report. J Histol Histopathol. 2015; 2:12.

http://dx.doi.org/10.7243/2055-091X-2-12 